\title{
Identificación de las técnicas de propagación y cultivo en residuos agroindustriales de hongos comestibles originarios de San Juan de Cacazú en la Selva central de la Amazonía peruana
}

\author{
Lucía Alejandra Fitts Vargas ${ }^{1}$ - Mardonio Enrique Palomino Agurto ${ }^{2}$ - Martín Araujo Flores ${ }^{3}$ \\ Universidad Nacional Agraria La Molina, Perú
}

Recepción: 25/07/2015

Aceptación: 25/08/2015

\section{Resumen}

El presente estudio tuvo por objetivo identificar las técnicas de propagación y cultivo más adecuadas para los hongos comestibles que crecen en la zona de San Juan de Cacazú, departamento de Pasco, Perú, para generar conocimientos que permitan implementar estas técnicas por la población local, proporcionando una alternativa de ingresos para las familias.

Se identificaron cuatro especies con gran potencial de consumo y presencia en la zona: Auricularia fuscosuccinea, A. delicata, A. polytricha y Pleurotus sp. Se entrevistó a pobladores de la zona acerca del consumo de los hongos y a los restaurantes de comida china de Villa Rica (Pasco-Perú). Se encontró que el 92\% de la población ha consumido alguna vez estos hongos; adicionalmente, más del 60\% reconoce a los hongos por sus nombres comunes. El $45.4 \%$ de hongos deshidratados utilizados por los restaurantes son importados de la China.

Palabras clave: hongos comestibles, Villa Rica, oreja de judas, Auricularia, Pleurotus

\begin{abstract}
This study aimed to identify the most suitable propagation and cultivation techniques for edible mushrooms, that grow in the area of San Juan de Cacazu, Pasco, Peru, to generate knowledge that allows to implement these techniques by local people, providing an alternative income for families.
\end{abstract}

Four species were identified with great consumption potential and presence in the area: Auricularia fuscosuccinea, A. delicata, A. polytricha yPleurotus sp. Residents of the area and Chinese food restaurants managers in Villa Rica (Pasco, Peru) were interviewed about the use of edible mushrooms. It was found that $92 \%$ of the population had used these mushrooms at least once before; in addition, more than $60 \%$ identify them by their common names. $45.4 \%$ of dried mushroom used by restaurants are imported from China.

Key words: edible mushrooms, Villa Rica, Jew's ear, Auricularia, Pleurotus

1. Bachiller en Ingeniería Forestal, e-mail: lucialafv92@gmail.com

2. Bachiller en Ingeniería Forestal, e-mail: mapagur@hotmail.com

3. Docente asesor de la Facultad de Ciencias Forestales, e-mail: maraujof@lamolina.edu.pe 


\section{Introducción}

Los hongos son consumidos tradicionalmente y utilizados como parte de la dieta alimenticia, debido al sabor, textura, propiedades medicinales y nutricionales; en algunos hogares son incluidos como reemplazo de la carne por su alto nivel de fibras y proteínas, de acuerdo a la data levantada. Al respecto, Gaitán-Hernández et al. (2002) menciona que, debido a la consistencia de las setas, con frecuencia se les denomina como «carne vegetal», ya que poseen características que los hacen un complemento alimenticio de gran valor, pudiéndose adecuar con facilidad a diferentes preparaciones culinarias, siendo aceptable su valor nutritivo comparado con otros alimentos.

En el Perú, el cultivo de hongos comestibles se inició en el año 1995 con la producción de champiñones (Agaricus bisporus); y posteriormente, el hongo ostra Pleurotus ostreatus (Gonzales, 2010). Sin embargo, actualmente existe una limitada disponibilidad de hongos comestibles provenientes de los bosques naturales amazónicos. En el centro poblado, San Juan de Cacazú, ubicado en el Departamento de Pasco, crecen una gran variedad de hongos comestibles, destacando los géneros Auricularia y Pleurotus. El consumo de estos hongos se ha dado mediante la recolección, por lo que su disponibilidad es limitada. Por otro lado, los pobladores han reducido su con- fluencia a los bosques, por lo que la recolección y consumo de hongos han disminuido progresivamente. El cultivo artificial de estos hongos y su comercialización contribuiría en generar beneficios socioeconómicos que mejoren la calidad de vida de los pobladores que se encuentran en condiciones de pobreza; y sobre todo, como alternativa nutricional.

Morales et al. (2002), citando a Sommerkamp (1990), indica que el valor nutritivo de los hongos se centra en su contenido vitamínico y mineral, similar al de las hortalizas comunes, conteniendo cantidades significativas de vitaminas del complejo B y C; y minerales como calcio, hierro, fósforo y potasio, importantes para una dieta balanceada. Señala además que poseen un alto contenido proteico y son bajos en calorías, carbohidratos y grasas.

Sobre las propiedades medicinales de los hongos, Ardón (2007) menciona que el género Auricularia se emplea en casos diversos, como en tratamientos hemorroidales, hasta en tratamientos antitumorales. Al respecto, Stamets (1993), citando a Ying (1987), indica que la especie Auricularia polytricha mostró efectividad en el tratamiento de neoplasias como el carcinoma Ehrlich y el sarcoma-180. Además, citando a Yuan et al. (1988), señala que se han realizado estudios con ratones con diabetes, los cuales presentaron efectos hipoglicémicos. Asimismo, menciona que esta especie posee propiedades anticoagulantes. Por 
otro lado, Palomo (1999) señala que el género Pleurotus tiene propiedades hematológicas, antivirales, antitumorales, renales y cardiovasculares.

Sobre las tecnologías de cultivo de hongos comestibles, Ríos y Ruiz (1993), citando a Singer (1964), indican que estas son variadas y que su uso y adaptación debe ser realizada para cada hongo comestible y en distintas condiciones y/o regiones. Asimismo, Talledo (2003) menciona que la calidad de la producción es dependiente de factores climáticos, características de la zona, materia orgánica disponible, y el manejo dado al bosque.

El cultivo artificial de hongos comestibles presenta una posibilidad de obtener grandes cantidades de producción en pequeñas áreas, mediante técnicas sencillas a bajo costo en períodos cortos de tiempo y con el empleo de residuos agroindustriales como sustratos (Villaseñor et al, 1997).

Para seleccionar el sustrato es indispensable conocer la disponibilidad y abundancia del mismo en la región en donde se piensa cultivar el hongo. Los sustratos más utilizados para el cultivo de estos hongos son las pajas de cebada, trigo, centeno, avena, arroz y sorgo; y en menor cantidad la pulpa de café y algunos bagazos como los de caña de azúcar y de maguey tequilero, así como aserrín, maíz, y en general rastrojos de cosecha. Algunas veces es recomendable hacer una combina- ción de substratos en diferente proporción, para incrementar la producción de hongos. (Gaitán-Hernández et al. 2006; Palomo, 1999; Talledo, 2003).

Ardón (2007) señala que hongos del género Auricularia crecen satisfactoriamente sobre subproductos agrícolas y agroindustriales como el bagazo de caña azúcar, olote de maíz, pajas de arroz, fibra de coco, aserrín de madera, lirio acuático, paja de trigo y pulpa de café combinado con aserrín.

\section{Materiales y métodos}

Como material biológico se utilizaron basidiocarpos de Auricularia fuscosuccinea, Auricularia delicata, Auricularia polytricha y Pleurotos sp. El sustrato vegetativo consistió en granos de trigo sancochado y de arroz crudo. El sustrato definitivo en rastrojo de paja, cascarilla de café (Coffea sp.) y aserrín de bolaina (Guazuma crinita). Se utilizaron los medios de cultivo: Papa Dextrosa Agar (PDA) y Extracto de Malta Agar (EMA). Finalmente, como reactivos se usaron hipoclorito de sodio, carbonato de calcio $(\mathrm{CaCO} 3)$ y yeso ( $\mathrm{CaSO} 4.2 \mathrm{H} 2 \mathrm{O})$.

La colección de basidiocarpos se realizó en la localidad de San Juan de Cacazú, sector Puellas, distrito Villa Rica, provincia de Oxapampa, región Pasco. Se trabajó en un fundo cuya extensión es de 167 hectáreas y un perímetro de 5 316metros. La altitud promedio de la zona es de 1200 a $1400 \mathrm{msnm}$. 
Se buscó obtener información local acerca del consumo e importancia de estos hongos para las personas. Se realizaron encuestas a 39 pobladores locales de San Juan de Cacazú (74\% mujeres y $26 \%$ hombres), y a once restaurantes de comida china de Villa Rica.

\section{Colección de hongos comestibles}

Se colectaron distintas especies de hongos a través de cinco recorridos realizados en tres ocasiones de aproximadamente dos horas cada uno: cuatro en San Juan de Cacazú, y un recorrido en el centro cafetalero "Aroma de Montaña”, situado en Villa Rica.

Para realizar la colecta se utilizaron dos modos de muestreo:

1. Transectos en un bosque secundario maduro, el cual tiene catorce años sin ningún tipo de intervención antrópica. Esta forma de colección se aplicó dos veces, y solamente en San Juan de Cacazú.

2. Colectas en lugares en los que ha habido alguna actividad agro-forestal en los últimos dos años, para lo cual se tomó una plantación de pino en San Juan de Cacazú, en la cual se había realizado una roza (tala rasa) y quema dieciocho meses atrás, y en Villa Rica en una plantación de café. El área muestreada en el primer caso fue de aproximadamente 1 ha y en el segundo, de 0.5 ha.
Para los transectos en bosque secundario, se realizó una evaluación preliminar en referencia al tipo de suelo del área de colecta, empleando el método de textura al tacto. Para la determinación de carbonatos se empleó agua oxigenada; y para hallar el pH se empleó jugo de limón.

La colecta consistió en extraer el cuerpo fructífero adjunto a un pedazo de corteza del tronco, empleando una cuchilla o navaja, el cual fue envuelto en papel toalla y colocado en una bolsa ziploc, la cual fue codificada con el nombre común y el número de colecta correlativo. Otra forma de almacenar la muestra colectada fue en tapers de plástico con hojas de papel toalla húmedas en el interior.

La identificación se realizó en el laboratorio de Tejidos Vegetales de la Universidad Peruana Cayetano Heredia, mediante claves para hongos basidiomicetos a cargo de la dra. Magdalena Pavlich.

\section{Siembra, cultivo y propagación}

Se seleccionaron individuos para su aislamiento y propagación en el Laboratorio de Preservación de la Madera de la Universidad Nacional Agraria La Molina. Luego, se limpiaron los cuerpos fructíferos con agua potable, se esterilizaron y desinfectaron con agua destilada e hipoclorito sódico (lejía) al 2\%, por aproximadamente un minuto, finalmente se lavaron con agua destilada estéril para retirar 
toda la lejía remanente. Los fructificaciones colectados se aislaron aplicando diferentes técnicas, las cuales se señalan a continuación:

\section{- Siembra directa en placas petri y tubos} de ensayo: Utilizando medios de cultivo de Papa Dextrosa Agar (PDA) y Extracto de Malta Agar (EMA), la cual consistió en recortar pequeños pedazos de los cuerpos fructíferos y colocarlos en los medios ya mencionados. De preferencia, se extrae un cuadrado de $0.5 \mathrm{~cm}$ de largo y ancho que se encuentre en la parte central del cuerpo fructífero y lo más pegado al pie del hongo posible.

- Colección de esporas por gravedad: Esta técnica utiliza dos juegos de placas petri pequeñas, estériles y descartables. Una tapa de uno de los juegos se pone por debajo de la parte cóncava de los cuerpos fructíferos y sirven como receptoras de esporas; se espera por unas 8 a 12 horas, se retiran los cuerpos fructíferos y las placas son selladas con la base del otro juego de placas petri que contenga medio de cultivo. Es decir, sólo se utiliza la tapa de un juego de placas y el receptor con medio de cultivo de la otra.

- Licuado y suspensión acuosa de esporas: Se limpió y desinfectó los cuerpos fructíferos que estaban en mejor estado, luego se licuaron con la mínima cantidad necesaria de agua destilada y estéril.
- Siembra: Una vez aislados los micelios de los hongos, se volvió a sembrar en nuevas placas Petri, a partir de las cuales se realizaron curvas de crecimiento y se analizó el dominio de estos hongos sobre las placas, las cuales se pueden observar en la figura 4. La cepa de cada uno de los hongos se propagó también en tubos de ensayo para futuras investigaciones.

Cuando se tuvo el micelio aislado y además purificado en placas con medio, se pasaron a granos de arroz (inóculo secundario o semilla), en los cuales el micelio creció hasta colonizar los granos. Esto es un paso previo a la siembra en las bolsas con sustrato. Marshal (2009) señala que en el proceso para la obtención del inóculo secundario se usan granos, los cuales comúnmente suelen ser semillas de sorgo, trigo, centeno, cebada, avena, mijo y arroz, entre otros cereales que se tengan a disposición.

- Propagación: El arroz fue remojado por aproximadamente 45 minutos, para que gane un poco de humedad y seguido de esto, se le adhirieron 13.5 gramos de yeso, y 3.5 gramos de carbonato de calcio por cada kilogramo seco de arroz. Luego de haber homogenizado todo, se pesaron bolsas de polipropileno de $8 \times 12$ "x2 con 200 gramos de arroz cada una, se sellaron y se esterilizaron dos veces. Cuando estu- 
vieron frías, luego de 24 horas, se procedió a colocar $1 / 3$ de cada placa, cubierta con el micelio por cada bolsa de 200 gramos; y se dejó en la incubadora por 15 días, tiempo en el cual el micelio recubrió toda la bolsa.

\section{Elaboración y siembra de sustratos}

Los sustratos seleccionados fueron: aserrín de bolaina (Guazuma crinita), cascarilla de café y rastrojo de paja de trigo, los cuales fueron remojados en agua por 24 horas para que absorbieran la humedad. Luego, por cada kilo de sustrato húmedo se utilizó 13.5 gramos de yeso, y 3.5 gramos de carbonato de calcio.

Se utilizaron tres combinaciones con los tres sustratos, colocándolos en proporciones diferentes, las cuales fueron:

Combinación A: $60 \%$ aserrín de bolaina, 20\% cascarilla de café y $20 \%$ rastrojo de paja.

Combinación B: $60 \%$ Rastrojo de paja, 20\% cascarilla de café y $20 \%$ aserrín de bolaina

Combinación C: 60\% Cascarilla de café, 20\% aserrín de bolaina y $20 \%$ rastrojo de paja

Se colocó un kilogramo de cada combinación en bolsas de polipropileno de 10x15"x2; luego fueron esterilizadas en dos ocasiones consecutivas, con espacios de 24 horas en autoclave a condiciones establecidas $\left(122^{\circ} \mathrm{C}\right.$ y en promedio a $124 \mathrm{kPa}$ ).
A 72 horas de haber pasado por la segunda esterilización, se procedió a realizar la siembra en cada combinación, por lo cual se introdujo aproximadamente 60 gramos de las semillas, preparadas previamente en el arroz en cada uno de los sustratos.

El tiempo de incubación va de 30 a 45 días en promedio (Borja, 2013 y Palomo, 1999). Luego de esto se abrió la parte superior de cada una de las bolsas, dejando una parte del micelio expuesto. Se las colocó bajo techo, donde recibían únicamente radiación indirecta para evitar que el sol reseque al hongo. El riego se dio dos veces al día (cada doce horas aproximadamente), con ayuda de un aspersor. Una vez que aparecieron las fructificaciones, se taparon las de A. fuscosuccinea con paños húmedos, los cuales las cubrían por completo para mantener su humedad. Éstas se destapaban durante tres a cuatro horas pasado el mediodía para que pudieran recibir luz. Las primeras dos semanas, se sumergieron cada dos o tres días en un recipiente con agua potable para permitir el ingreso de agua, sin saturarlos demasiado para evitar la aparición de bacterias.

Con las cosechas progresivas realizadas para cada uno de los panetones (bolsas con sustrato), se calculó la eficiencia biológica, relacionando el peso húmedo del hongo sobre el peso seco del sustrato antes de iniciar el tratamiento. Con los resultados se realizó un análisis de varianzas y la prueba estadística de Tuckey. 


\section{Resultados y discusión}

Encuestas a la población local y restaurantes de comida china

Se obtuvo una mayor frecuencia de consumo de hongos en época de lluvia (55\%) y el 45\% restante se da eventualmente según su disponibilidad.

Con respecto a la forma de consumo, se obtuvieron respuestas múltiples (no excluyentes), dentro de las cuales frecuentaba el preparar los hongos fritos y salteados. Dentro de los motivos de consumo más frecuentes por los pobladores, se obtuvo que el 51\% los consume por el sabor que adoptan al ser cocinados en diferentes comidas. En la figura 1 se muestran los resultados obtenidos.

El total de los restaurantes encuestados utilizan hongos del género Auricularia en sus comidas, adquiriéndolos de forma mensual en una presentación deshidratada. El lugar de abastecimiento más resaltante fue el "Barrio chino" (Lugar ubicado en el centro comercial de Lima, donde se comercializan gran cantidad de productos y servicios de origen chino), con un $45.45 \%$, y una tienda local que abastece a restaurantes pequeños, cuyo producto "hongos Auricularia" también es provenientes de Lima (18.18\%). El 27\% de los encuestados no especificó la procedencia del hongo, y únicamente un $9.09 \%$ utilizan hongos de la zona.

Cabe resaltar que, si bien en la zona los hongos comestibles crecen de forma natural, los restaurantes de comida china encuestados siguen prefiriendo comprar los hongos importados, debido a la falta de tecnología en el procesamiento post cosecha y la temporalidad de su abastecimiento. Los hongos de procedencia nacional - al poco tiempo de ser comprados y almacenados - eran propensos al ataque de insectos y hongos; esto probablemente causado por procesamientos inadecuados. El precio de $1 \mathrm{~kg}$ de hongos de

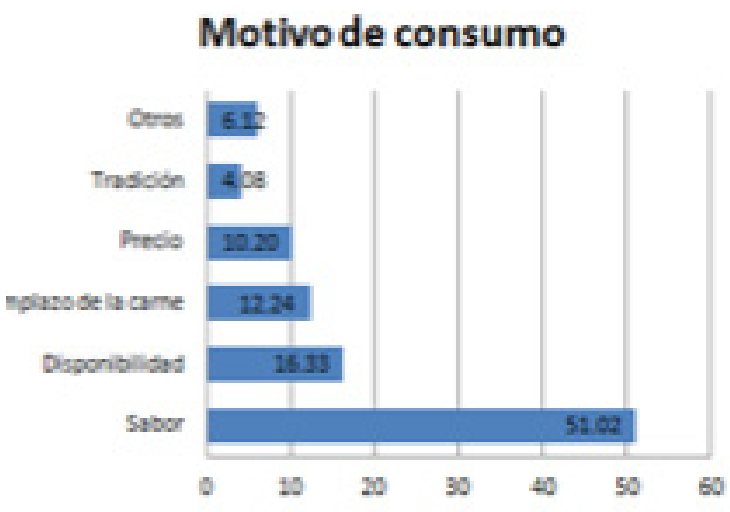

\section{Forma de consumo}

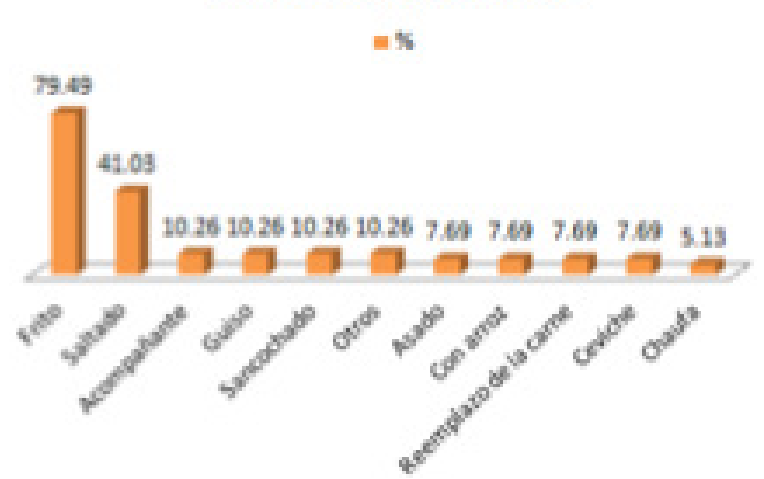

Figura 1. Forma y motivo de consumo de los hongos comestibles por los pobladores locales de San Juan de Cacazú, Perú. 
procedencia nacional es de $\$ 18$, mientras que el importado de la China cuesta entre $\$ 20$ y 15 dólares.

\section{Condiciones de los troncos donde se encon- traron hongos}

De las colectas, se pudo notar que tanto las especies colectadas del género Auricularia como Pleurotus crecían sobre troncos podridos o en proceso de descomposición, los cuales no se encontraban cubiertos por musgo ni líquenes. Adicionalmente, en todos los casos se notó que existía alguna fuente de agua al costado o cerca a los hongos recolectados, ya sea alguna quebrada, cascada, etc. El tipo de suelo donde se colectaron es franco limoso (85\% arcillas y 15\% limo), con un nivel medio de carbonatos y el pH de este suelo es ácido.

Los hongos del género Auricularia crecían en la parte inferior o lateral de los troncos, no se encontraron cuerpos fructíferos en la parte superior de los mismos. Además, las condiciones lumínicas eran básicamente radiación indirecta (sombra), tanto dentro de los transectos del bosque como en las chacras de café y plantaciones de pino, las cuales presentaban también la misma radiación.

Los troncos en donde se recolectaron las fructificaciones fueron hallados en el transecto. Entre estos se encontraban: matapalo (Ficus sp.), pacae rojo (Inga sp.), roble, roble alcanfor y huampo (Heliocarpus sp.), siendo los más comunes las Ingas y Ficus, las cuales son maderas blandas.

Al respecto, Talledo (2003) menciona que el género Auricularia crece sobre ramas de árboles caducifolios, especialmente en sauco (género Sambucus), café (género Coffea) o guayaba (Psidium guajava), con cierto grado de descomposición. También suele aparecer en troncos viejos de sauces (Salix sp.) y nogales (Juglans sp.).

Varios factores parecen determinantes en la colonización de la madera: el primero es que el tiempo transcurrido por el árbol en el bosque sea suficiente para que se produzca su colonización; el segundo y más importante, es el grado de alteración del substrato, esto lleva consigo dos cambios notables en la madera, pues a medida que se descompone se vuelve más blanda y menos consistente. Durante mucho tiempo la capa superficial permanece dura y rígida, como consecuencia de la alteración. En la fase final de la descomposición, ésta se ablanda debido a la ruptura de las fibras. Finalmente, el grado de descomposición es también un factor determinante de la población en un instante dado (Martín, I., \& Hladun, 1983).

\section{Identificación de hongos colectados}

Se identificaron tres especies del género $\mathrm{Au}$ ricularia: A. fuscosuccinea, A. delicata y A. polytricha y una especie del género Pleurotus: 
Pleurotus sp. El género Auricularia se encuentra mayormente en regiones tropicales y subtropicales (Palomo, 1999), y se encuentra presente en la selva del Perú. En la figura 2 se muestran las fotografías de cada uno de los hongos y en la figura 3, su clasificación taxonómica.

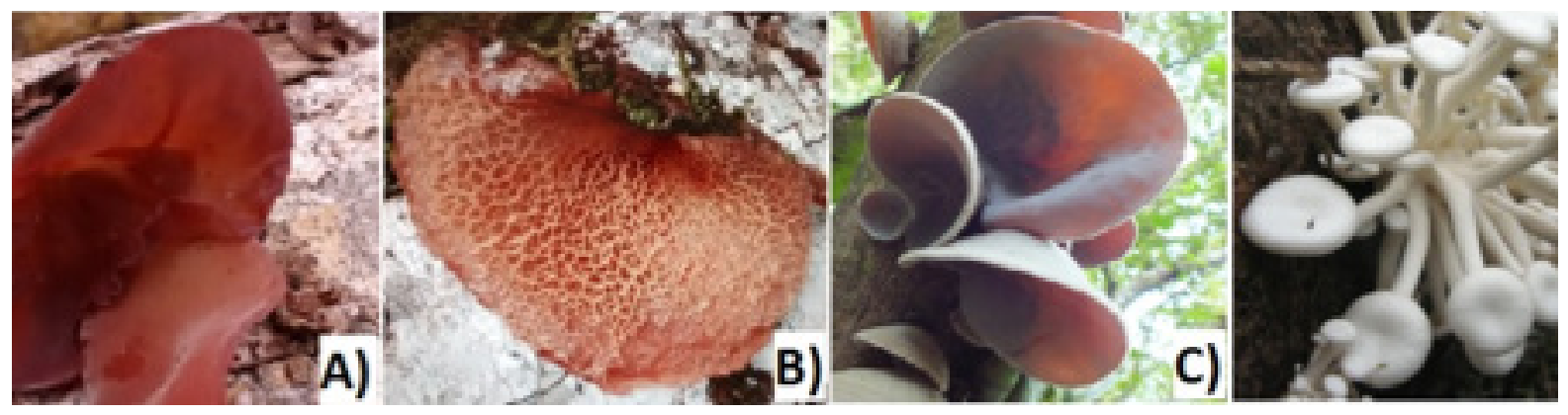

Figura 2. Fructificaciones colectadas en campo A: A. fuscosuccinea, B: A. delicata, C: A polytricha, D: Pleurotus sp.

\begin{tabular}{|c|c|c|c|c|c|c|c|c|}
\hline No & $\begin{array}{c}\text { Nombre } \\
\text { común }\end{array}$ & Especie & Género & Familia & Orden & Clase & División & Reino \\
\hline 1 & Oreja & $\begin{array}{c}\text { Fuscosuc- } \\
\text { cinea }\end{array}$ & $\begin{array}{c}\text { Auricu- } \\
\text { laria }\end{array}$ & $\begin{array}{c}\text { Auricula- } \\
\text { riaceae }\end{array}$ & $\begin{array}{c}\text { Auricula- } \\
\text { riales }\end{array}$ & $\begin{array}{c}\text { Agarici- } \\
\text { comycetes }\end{array}$ & $\begin{array}{c}\text { Basi- } \\
\text { diomycota }\end{array}$ & Fungy \\
\hline 2 & $\begin{array}{c}\text { Mondongo } \\
\text { de venado }\end{array}$ & delicata & $\begin{array}{c}\text { Auricu- } \\
\text { laria }\end{array}$ & $\begin{array}{c}\text { Auricula- } \\
\text { riaceae }\end{array}$ & $\begin{array}{c}\text { Auricula- } \\
\text { riales }\end{array}$ & $\begin{array}{c}\text { Agarici- } \\
\text { comycetes }\end{array}$ & $\begin{array}{c}\text { Basi- } \\
\text { diomycota }\end{array}$ & Fungy \\
\hline 3 & Oreja & polytricha & $\begin{array}{c}\text { Auricu- } \\
\text { laria }\end{array}$ & $\begin{array}{c}\text { Auricula- } \\
\text { riaceae }\end{array}$ & $\begin{array}{c}\text { Auricula- } \\
\text { riales }\end{array}$ & $\begin{array}{c}\text { Agarici- } \\
\text { comycetes }\end{array}$ & $\begin{array}{c}\text { Basi- } \\
\text { diomycota }\end{array}$ & Fungy \\
\hline 4 & $\begin{array}{c}\text { Charqui } \\
\text { Charqui }\end{array}$ & sp. & Pleurotus & $\begin{array}{c}\text { Pleurota- } \\
\text { ceae }\end{array}$ & Agaricales & $\begin{array}{c}\text { Agarici- } \\
\text { comycetes }\end{array}$ & $\begin{array}{c}\text { Basi- } \\
\text { diomycota }\end{array}$ & Fungy \\
\hline
\end{tabular}

Figura 3. Clasificación taxonómica de los hongos colectados

El cuerpo fructífero de la especie Auricularia fuscosuccinea presenta un aspecto gelatinoso; es delgado con una textura lisa tanto al interior como al exterior y un color que varía entre vino y palo rosa. La Auricularia delicata es también gelatinosa, pero un poco más gruesa y con textura lisa en la parte exterior y rugosa por la parte interior con un aspecto similar a venas o nervios. Su color es más claro, con un tono crema medio rosado o canela. Con respecto a la Auricularia polytricha, es de contextura más dura y resistente; presenta una capa de vellosidades en la parte externa y el lisa por la parte interior. Su color es grisáceo en la parte exterior y un palo rosa para la parte interior.

\section{Propagación de los hongos utilizando medios} de cultivos artificiales

\section{Siembra y aislamiento}

Siembra directa en placas petri y tubos de ensayo: Tuvo resultados satisfactorios para Auricularia polytricha y Pleurotus sp 
Colección de esporas por gravedad: La cual dio resultados satisfactorios para Auricularia fuscosuccinea.

Licuado y suspensión acuosa de esporas: La cual resultó satisfactoria para Auricularia delicata.

Durante el aislamiento se registraron contaminantes en las placas, siendo los más comunes bacterias, así como otros hongos que suelen estar en el ambiente como Aspergillus sp, Penicillium sp, Trichoderma sp, Pestalotia sp, entre otros. Se notaron en algunas placas la presencia de ácaros de polvo.
El tiempo promedio de llenado de la placa de cada una de las especies trabajadas fue de ocho días para Auricularia delicata; doce días para Pleurotus sp., y de dieciséis días para Auricularia fuscosuccinea. El crecimiento de cada uno de los mismos se puede observar en la figura 4, para el cual se midieron y promediaron los diámetros de ejes de $90^{\circ}$; y se utilizaron tres repeticiones para Pleurotus sp.; siete repeticiones para Auricularia delicata y cuatro repeticiones para Auricularia fuscosuccinea. En la figura 4 muestra las curvas de crecimiento para cada especie.

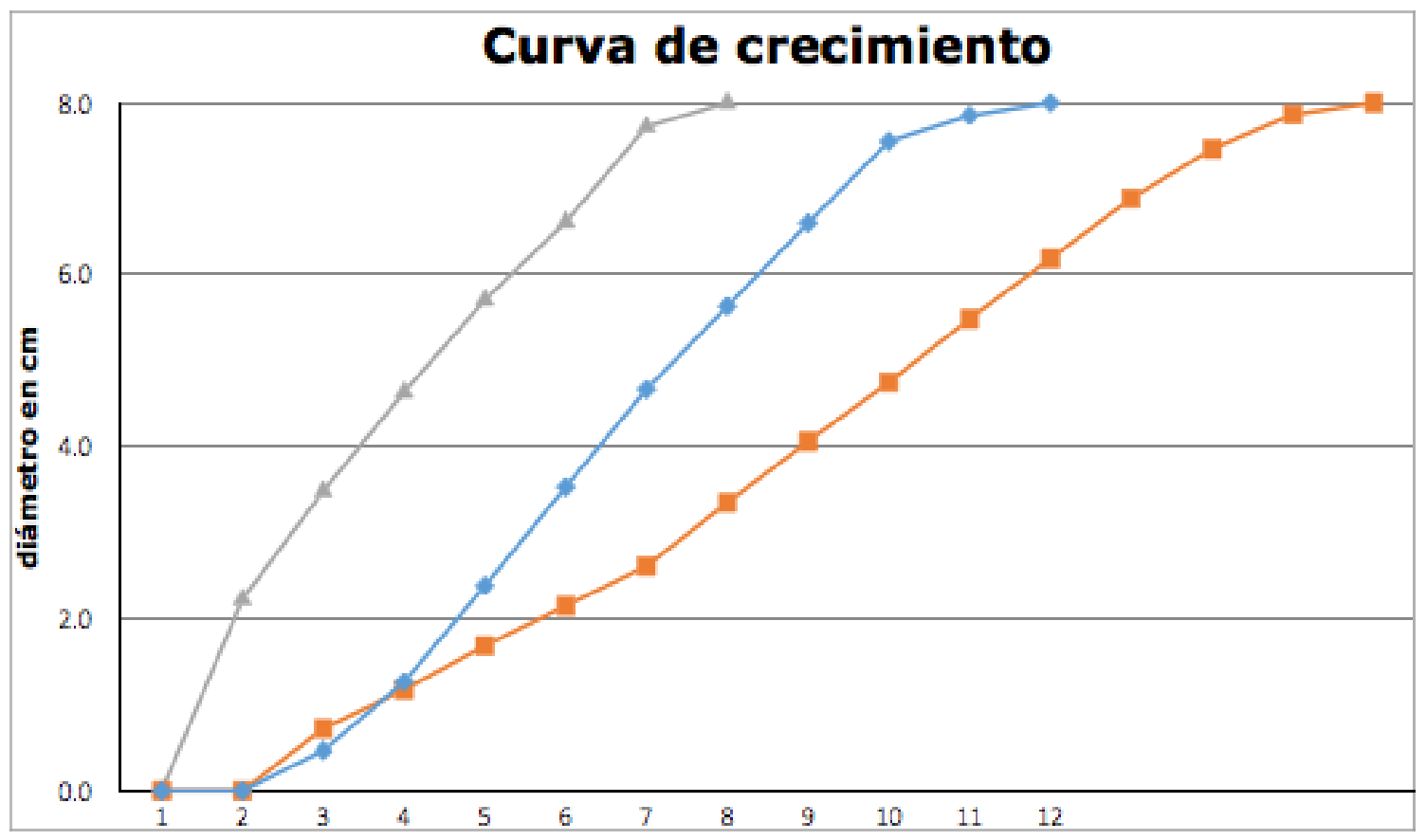

Figura 4. Curva de crecimiento para 3 especies de hongos aislados

Temperaturas óptimas para incubación de las placas para el género Auricularia son entre los $20-30^{\circ} \mathrm{C}$; y temperaturas de producción de entre 16 y $20^{\circ} \mathrm{C}$. El tiempo promedio de incubación es de 15 días (Talledo, 2003). 


\section{Elaboración de semillas}

De las semillas (inóculo primario) preparadas de todos los hongos identificados utilizando trigo y arroz, el tiempo promedio de colonización fue de una semana y media a dos semanas en incubadora a $30^{\circ} \mathrm{C}$; lo que coincide con lo señalado por Talledo (2003). Las semillas que colonizaron más rápido fueron las de Pleurotus sp., seguidas por las de Auricularia fuscosuccinea. Las semillas de Auricularia delicata y Auricularia polytricha tardaron de una semana y media a dos semanas en colonizar.

Se notó un crecimiento más rápido en semillas de arroz respecto a las de trigo, las cuales presentaron problemas de contaminación principalmente por bacterias. Otros hongos contaminantes que se notaron fueron: Penicillium sp., Trichoderma sp., entre otros no identificados con coloraciones amarillas y rojas.

\section{Elaboración de sustratos}

Para pasar al sustrato definitivo se trasladó directamente el inóculo primario (semillas) a la bolsa con sustrato esterilizado, sin pasar por un proceso de fermentación (de tres días) recomendado por Talledo (2003). De los tres tipos de sustrato:

A: mayor proporción de aserrín;

B: mayor proporción de paja de trigo, y

C: mayor proporción de cascarilla de café).
En el tipo A, se observó que el micelio correspondiente a ambas especies colonizó más rápido y con mayor vigor. Por otro lado, estos se tornaron casi impermeables, por lo que para el riego se hicieron pequeños cortes en el sustrato para facilitar el ingreso de agua. El periodo de colonización de los sustratos definitivos fue de un mes y medio a dos meses.

La aparición de las primeras fructificaciones se dio a las dos y tres semanas de la apertura de las bolsas en los sustratos tipo A y C. Las demás fructificaciones tardaron de tres semanas hasta casi dos meses en aparecer.

La densidad de fructificaciones para A. fuscosuccinea en los distintos sustratos fue variable. En el sustrato tipo A aparecieron de dos a tres cuerpos fructíferos al mismo tiempo; sin embargo, estos crecieron hasta diámetros de 15 a $18 \mathrm{~cm}$. En los sustratos tipo B y C, los cuales por su composición era más porosa, se observó una densidad muy alta, llegando a aparecer decenas de fructificaciones en un espacio reducido. No obstante, pocas de estas desarrollaban al mismo tiempo y no llegaban a diámetros superiores a 5 a $7 \mathrm{~cm}$. Por otro lado, la especie Pleurotus sp. creció únicamente en el sustrato A, y aparecieron de dos a tres fructificaciones a cada lado, y cada una presentó entre 16 y 35 primordios individuales.

A las dos semanas de la apertura de bolsas, justo antes de la aparición de los primordios, los panetones de Auricularia fuscosuccinea se cubrieron de una capa babosa y gelatinosa. Luego apa- 
recieron los primordios como pequeños bultos. Los hongos estudiados especialmente la A. fuscosuccinea son muy sensibles a la humedad, por lo que presentaron muy buen comportamiento al taparlos con paños húmedos y rociarlos con agua mediante aspersores dos veces al día (cada doce horas), una vez que aparecieron las fructificaciones y empezaban a desarrollar. Estos paños se destaparon por unas tres a cuatro horas; pasado el mediodía cuando la intensidad del sol no era muy alta, para evitar que se resecaran y pudieran recibir la luz que requerían.

Se observó que en A. fuscosuccinea fructificaba principalmente en los costados del panetón, puesto a que estas naturalmente cuelgan hacia abajo asemejando a una campana. En el caso de Pleurotus sp., las fructificaciones aparecían en la parte superior y en los costados superiores.

Dentro de los cuerpos fructíferos que crecieron en los panetones, se tomaron muestras de ambas especies para el sustrato aserrín, ya que las dimensiones resultantes eran más similares a las encontradas en campo y se midieron sus diámetros en ambos ejes. Para la especie Auricularia fuscosuccinea se encontraron diámetros con un rango desde $5.85 \mathrm{~cm}$ hasta $15.25 \mathrm{~cm}$, y para el Pleurotus sp., un diámetro que varía entre $4.15 \mathrm{~cm}$ hasta $6.4 \mathrm{~cm}$. Se determinó adicionalmente el contenido de humedad en base húmeda para dichas fructificaciones, obteniendo $89.97 \%$ para Auricularia fuscosuccinea y 80.27 \% para Pleutorus sp. La figura 5 mues- tra las fructificaciones de los hongos cultivados. (Ver figura 5)

Con respecto a los contaminantes y plagas que afectaron esta etapa del proyecto se tienen hongos de humedad como Penicillium sp., Trichoderma sp., entre otros no identificados con coloraciones negras. Las plagas presentes fueron mosquitos pequeños y sus respectivas larvas, las cuales carcomen al cuerpo fructífero y micelio de los hongos estudiados. Palomo (1999) señala que plagas y enfermedades comunes para los cultivos de hongos comestibles son otros hongos, bacterias, virus, nemátodos y también moscas y ácaros. Asimismo señala que pueden presentarse anomalías en el crecimiento, por malos acondicionamientos de temperatura y humedad en los cuartos de fructificación; e incluso, se pueden presentar anomalías genéticas.

Se compararon los datos obtenidos de la especie Auricularia fuscosuccinea para determinar si la masa total de cuerpos fructíferos obtenida difiere entre cada uno de los tratamientos. Para esto se realizó un análisis de varianza y la prueba de Tuckey con un $\alpha=0.05$ con lo cual se rechazó la hipótesis nula de igualdad de tratamientos y se aceptó la hipótesis alternante; por lo que existe evidencia estadística para afirmar que los tratamientos difieren entre sí. Los resultados de las pruebas se pueden observar en los cuadros 1 y 2 . Se observa una diferencia significativa entre los sustratos de aserrín y paja, así como entre aserrín y cascarilla de café. Sin embargo, no se encontró diferencia significativa entre los sustratos paja $y$ cascarilla de café. 

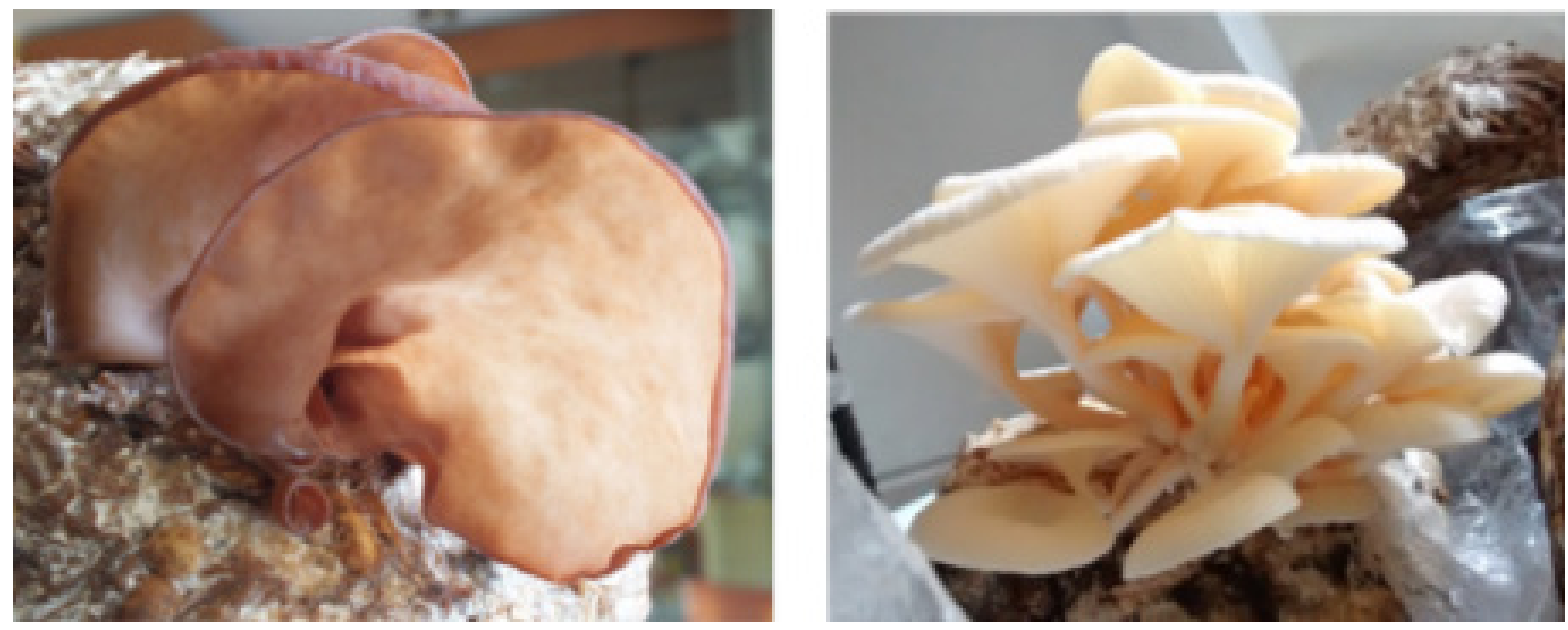

Figura 5. Fructificación de Auricularia fuscosuccinea (izquierda) y Pleurotus sp. (derecha).

Cuadro 1. ANOVA para las masas de los cuerpos fructíferos de Auricularia fuscosuccinea

\begin{tabular}{|c|c|c|c|c|c|}
\hline & $\begin{array}{c}\text { Suma de } \\
\text { cuadrados }\end{array}$ & gl & $\begin{array}{c}\text { Media } \\
\text { cuatrática }\end{array}$ & F & Sig. \\
\hline Sustrato & 23064.354 & 2 & 11532.177 & 28.280 & .000 \\
\hline Error & 2854.503 & 7 & 407.786 & & \\
\hline Total & 25918.857 & 9 & & & \\
\hline
\end{tabular}

Cuadro 2. Prueba de Tuckey para las masas de los cuerpos fructíferos de Auricularia fuscosuccinea

\begin{tabular}{|c|c|c|c|c|c|c|}
\hline \multirow[b]{2}{*}{ Sustrato } & \multirow{2}{*}{$\begin{array}{c}\text { (J) } \\
\text { sustrato }\end{array}$} & \multirow{2}{*}{$\begin{array}{l}\text { Diferencia de } \\
\text { medidas (I-J) }\end{array}$} & \multirow{2}{*}{ Error típico } & \multirow{2}{*}{ Sig. } & \multicolumn{2}{|c|}{$\begin{array}{l}\text { Intervalo de confianza } \\
\text { al } 95 \%\end{array}$} \\
\hline & & & & & $\begin{array}{l}\text { Límite } \\
\text { inferior }\end{array}$ & $\begin{array}{l}\text { Límite } \\
\text { superior }\end{array}$ \\
\hline \multirow[b]{2}{*}{ Aserrín } & Paja & 102.1557667 & 15.4232052 & .001 & 56.733527 & 147.578007 \\
\hline & $\begin{array}{l}\text { Cascarilla } \\
\text { de café }\end{array}$ & 108.0134667 & 16.4880999 & .001 & 59.455050 & 156.571884 \\
\hline \multirow[b]{2}{*}{ Paja } & Aserrín & -102.1557667 & 15.4232052 & .001 & -147.578007 & -56.733527 \\
\hline & $\begin{array}{l}\text { Cascarilla } \\
\text { de café }\end{array}$ & 5.8577000 & 15.4232052 & .924 & -39.564540 & -39.564540 \\
\hline \multirow{2}{*}{$\begin{array}{l}\text { Cascarilla } \\
\text { de café }\end{array}$} & Aserrín & -108.0134667 & 16.4880999 & .001 & -156.571884 & -156.571884 \\
\hline & Paja & -5.8577000 & 15.4232052 & .924 & -51.279940 & -51.279940 \\
\hline
\end{tabular}


Con los valores obtenidos, se realizó un diagrama de cajas, como se observa en la figura 6, en el que se comprueba las diferencias encontradas en las pruebas estadísticas.

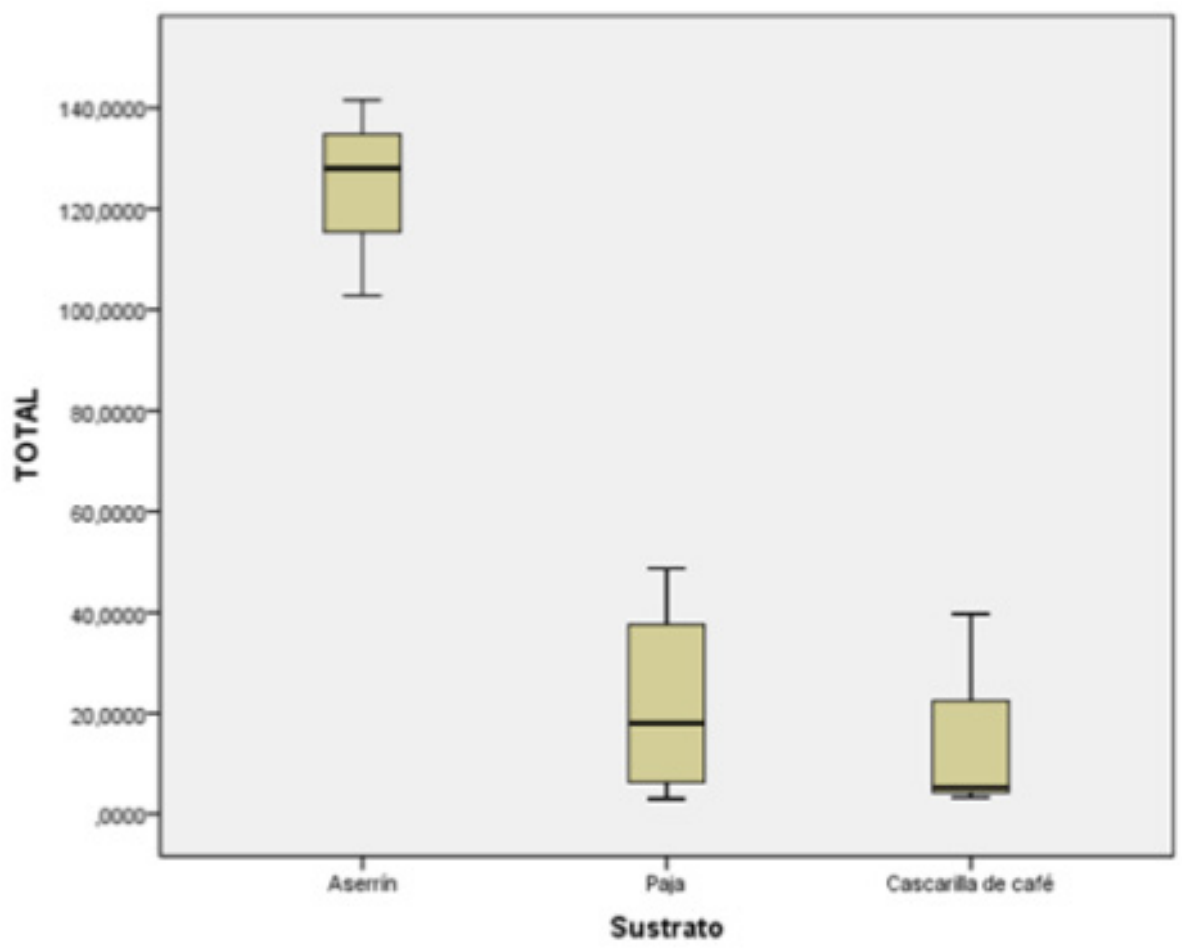

Figura 6. Diagrama de cajas para la masa total colectada en cada uno de los sustratos empleados en Auricularia fuscosuccinea

Con los valores obtenidos se observa en el cuadro dos, que el tratamiento con el sustrato de mayor proporción de aserrín (tipo A) es el que presenta una mayor eficiencia biológica, y por lo tanto, el que deberá ser utilizado para la propagación y cultivo de esta especie.

Cuadro 3. Masa de los cuerpos fructíferos y eficiencia biológica

\begin{tabular}{|l|l|l|l|}
\hline \multicolumn{1}{|c|}{ Especie } & \multicolumn{1}{|c|}{ Sustrato } & \multicolumn{1}{c|}{$\begin{array}{c}\text { Masa cuerpos } \\
\text { fructíferos (g) }\end{array}$} & \multicolumn{1}{c|}{$\begin{array}{c}\text { Eficiencia } \\
\text { biológica \% }\end{array}$} \\
\hline $\begin{array}{l}\text { Auricularia fuscosuc- } \\
\text { cinea }\end{array}$ & Aserrín & 141.62 & 50.88 \\
\hline $\begin{array}{l}\text { Auricularia fuscosuc- } \\
\text { cinea }\end{array}$ & Aserrín & 127.97 & 45.98 \\
\hline $\begin{array}{l}\text { Auricularia fuscosuc- } \\
\text { cinea }\end{array}$ & Aserrín & 102.77 & 36.92 \\
\hline $\begin{array}{l}\text { Auricularia } \\
\text { fuscosuccinea }\end{array}$ & Paja & 48.70 & 13.73 \\
\hline
\end{tabular}




\begin{tabular}{|c|c|c|c|}
\hline Especie & Sustrato & $\begin{array}{l}\text { Masa cuerpos } \\
\text { fructíferos (g) }\end{array}$ & $\begin{array}{c}\text { Eficiencia } \\
\text { biológica \% }\end{array}$ \\
\hline Pleurotus sp. & Aserrín & 45.37 & 16.30 \\
\hline Pleurotus sp. & Aserrín & 45.00 & 16.17 \\
\hline $\begin{array}{l}\text { Auricularia } \\
\text { fuscosuccinea }\end{array}$ & Cascarilla de café & 39.67 & 5.18 \\
\hline Pleurotus sp. & Aserrín & 35.06 & 12.60 \\
\hline $\begin{array}{l}\text { Auricularia } \\
\text { fuscosuccinea }\end{array}$ & Paja & 26.41 & 7.44 \\
\hline $\begin{array}{l}\text { Auricularia } \\
\text { fuscosuccinea }\end{array}$ & Paja & 9.71 & 2.74 \\
\hline $\begin{array}{l}\text { Auricularia } \\
\text { fuscosuccinea }\end{array}$ & Cascarilla de café & 5.30 & 0.69 \\
\hline $\begin{array}{l}\text { Auricularia } \\
\text { fuscosuccinea }\end{array}$ & Cascarilla de café & 3.35 & 0.44 \\
\hline $\begin{array}{l}\text { Auricularia } \\
\text { fuscosuccinea }\end{array}$ & Paja & 3.04 & 0.86 \\
\hline Pleurotus sp. & Paja & 0.00 & 0.00 \\
\hline Pleurotus sp. & Cascarilla de café & 0.00 & 0.00 \\
\hline Pleurotus sp. & Paja & 0.00 & 0.00 \\
\hline Pleurotus sp. & Paja & 0.00 & 0.00 \\
\hline Pleurotus sp. & Paja & 0.00 & 0.00 \\
\hline Pleurotus sp. & Cascarilla de café & 0.00 & 0.00 \\
\hline
\end{tabular}

En cuanto a su eficiencia biológica, el sustrato tipo A presentó una media de 44.59, y una desviación estándar de 7.08. El tipo B muestra una media de 6,19 y una desviación estándar de 5,74 y el tipo C de 2,1 y 2,67 de media y desviación estándar respectivamente.

Con respecto a la especie Pleutorus sp. No se realizaron pruebas estadísticas adicionales debido a que en el único sustrato que se obtuvieron resultados fue el tipo A. Se sugiere utilizar este sustrato; sin embargo, se deben seguir proban- do otras combinaciones de insumos para un resultado más óptimo.

El proceso completo de propagación y cultivo duró aproximadamente 4 meses desde que ya se tenía la sepa aislada, de los cuales 12 días para la propagación del micelio $\left(25-30^{\circ} \mathrm{C}\right), 15$ días para la colonización de las semillas $\left(25-30^{\circ} \mathrm{C}\right), 60$ días para la colonización del sustrato definitivo $\left(17-20^{\circ} \mathrm{C}\right)$ y 30 días hasta que inicia la cosecha. 


\section{Conclusiones}

El 92\% de la población local ha consumido alguna vez los hongos estudiados. Adicionalmente, más del $60 \%$ de pobladores reconoce a los hongos por sus nombres comunes.

El sustrato más adecuado para Auricularia fuscosuccinea y Pleurotus sp. fue el que contenía mayor proporción de aserrín, debido a una eficiencia biológica más elevada.

Para Pleorotus sp, el mejor método de siembra fue el utilizado directamente en campo. Para el género Auricularia se determinó que el mejor método de cultivo fue el de colecta de esporas por gravedad. Para ambas especies se determinó que la propagación en arroz crudo para obtener los inóculos primarios y secundarios fue la más adecuada, y el sustrato definitivo con mayor proporción de aserrín.

Para la obtención de esta información se agradece, especialmente al ing. Jorge Luis Gómez, dra. Magdalena Pavlich de la Universidad Peruana Cayetano Heredia. Al sr. Miguel, Carlos Torres, Danilo y al ing. Judith Echegaray de SENASA. También a Jaime Borja de la Universidad Nacional Agraria La Molina y a Héctor Centeno de Fundo Aroma de Montaña.

\section{Referencias}

Álvaro, N. L. (1983). Observaciones sobre la colonización briológico-liquénica de la madera en descomposición en los bosques del Moixero (Catalunya). Collectanea Botanica, vol. 14, p. 19-25. Recuperado de: http://diposit.ub.edu/dspace/bitstream/2445/30882/1/007819.pdf

Ardón, C. (2007). La producción de hongos comestibles. Guatemala: Universidad de San Carlos de Guatemala. 128-129

Gaitán-Hernández, R., Salmones, D., Merlo, R. P. y Mata, G. (2002). Manual práctico del cultivo de setas: aislamiento, siembra y producción. Instituto de Ecología, Xalapa, Ver. México

Gonzales, J. (2010). Evaluación de tratamientos de conservación del hongo ostra (Pleurotus ostreatus) mediante encurtidos dulces y salados para darle valor agregado. Madre de Dios: Universidad Nacional Amazónica de Madre de Dios

Morales, O., Bran, M., Cáceres, R. y Flores, R. (2002). Contribución al conocimiento de los hongos comestibles de Guatemala. p1. Recuperado de: http://www.hongoscomestibles-latinoamerica.com/P/P/30.pdf 
Palomo, A. (1999). Cultivo de hongos comestibles en el trópico ¿Hongos comestibles o Champiñones? Agronomía, 45, 59-62

Ríos, R. y Ruiz, L. (1993). Aislamiento y cultivo del hongo comestible Pleurotus afín ostreatus (jackq ex Fr) Kumm en Tingo María. Folia Amazónica, 13, 5-14

Stamets, P. (1993). Growing Gourmet and Medicinal Mushrooms. 3rd edition. 396-400

Talledo, G. (2003). Cultivo de Oreja de Judas (Auricularia Auricularia Judae). Agroenfoque, 19, 20-22

Villaseñor, L; Rodríguez, O. y Arias, A. (1997). Hongos comestibles que podemos cultivar. Guadalajara, México: El Informador 